\title{
RECOVERY OF REEF COMMUNITIES AFTER THE TRIASSIC MASS EXTINCTION
}

George D. Stanley, Jr., Department of Geology, University of Montana, Missoula MT 59812, USA

During the Late Triassic reef framework became increasingly dominated by zooxanthellate corals while chambered sponges, spongiomorphs, calcareous algae, and problematica inherited from earlier reef intervals were also important players. Since tropical reef ecosystems are among the most ecologically sensitive to perturbations in the global marine environment, their study offers insights not only into extinction dynamics but recoveries as well. Reef ecosystems evolved through several crucial steps from the Permian to the end of the Triassic within the tropical to subtropical Tethys seaway. Thanks to detailed field and taxonomic studies of Triassic reef ecosystems, excellent data is available for latest Triassic (Norian-Rhaetian) interval.

In a fashion congruent with other marine ecosystems, Late Triassic reefs suffered major setbacks at the end of the period some 200 mya. Although quality and nature of these data vary considerably across various marine ecosystems, reefs experienced proportionally greater losses and recovery was slower. Data from Eurasia also suggests that reef ecosystems collapsed suddenly in an abrupt Tethys-wide event. An ensuing Early Jurassic reef eclipse lasted from 4-10 ma. Among 321 Triassic coral species only 14 are known from earliest Jurassic rocks of the Tethys. Among 58 genera of Triassic thalamid reef sponges only five are documented to have survived. Except for one species all chambered "spinctozoan" sponges, so important in Late Triassic reefs, failed to survive. Full recovery of the ecosystem was not complete until Mid-Jurassic time when fully developed coral, sponge, and hydrozoan reefs emerged in reef settings of the Tethys.

A meager but growing record of Triassic reef ecosystems from Cordilleran tectono-stratigraphic terranes represents tropical oceanic islands of the ancient Pacific. Corals, sponges and other organisms provide tantalizing glimpses of reef evolution and recovery at sites isolated from the Tethys. These vanished islands of the ancient Pacific appear to have functioned as refuges not only for survival of Triassic taxa into the Jurassic but perhaps also for Permian taxa into the Triassic. Repopulation of the Tethys was a very rapid event. 